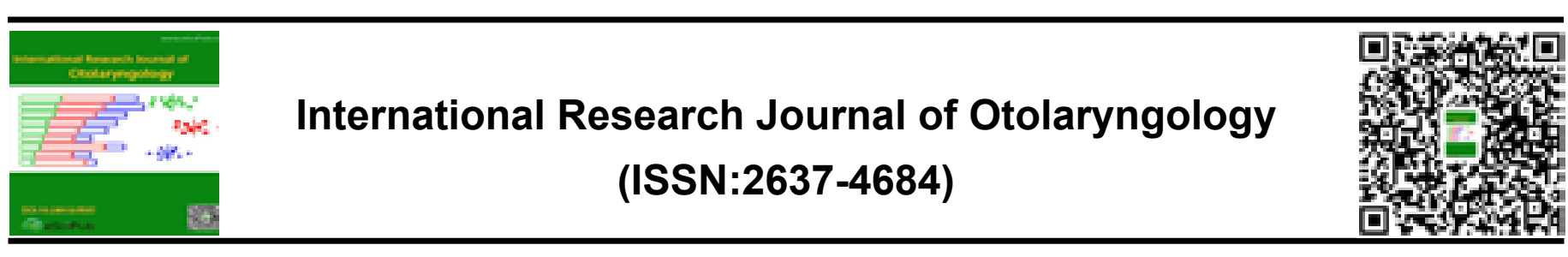

\title{
DERMOID CYST ENUCLEATION IN HEARING PAVILION
}

Camilla Siqueira de Aguiar ${ }^{1 *}$, Evellyn Rayane Martins de Oliveira ${ }^{1}$, Lohana Maylane Aquino Correia de Lima ${ }^{1}$, Victor Leonardo Mello Varela Ayres de Melo", Maria Luísa Alves Lins ${ }^{1}$, Ricardo Eugenio Varela Ayres de Melo'

${ }^{1}$ UFPE

\section{ABSTRACT}

Introduction The dermoid cyst is a rare cystic malformation, classified as benign cystic teratoma. It is bordered by an epidermal-like epithelium, containing structures attached to its wall. These cysts originate from midline retained epithelial remains during the closure of the mandibular branchial arches and the hyoid bone. The prevalence in the head and neck region is low. They affect more young adults without a predilection for sex. Clinically, it presents as a swelling, of soft consistency upon palpation because it contains keratin remnants and sebaceous secretions inside. The lesion is usually about $2 \mathrm{~cm}$ in diameter. Surgical excision is the treatment of choice, with little risk of relapse. Objective To report the clinical case of a 16-year-old male patient who underwent cystic lesion excision in the ear region with a diagnosis of dermoid cyst. Methodology The methodology of the study was the search for articles related to the subject, organization in a brief literature review and its comparison with the case report that was described. Results A 16-year-old male patient, melanoderma, sought the Oral Maxillo Facial Surgery and Traumatology Service of the Federal University of Pernambuco of School Dentistry, reporting an increase in volume in the right post-auricular region with approximately 3 years of evolution. On clinical examination, a well-circumscribed lesion without movement, soft to palpation and painless was observed. The patient underwent additional examinations and excisional biopsy under general anesthesia. The access started with an incision in the post-auricular region, followed by the myocutaneous tissue division until the lesion was visualized and soon after, the dissection of the adjacent tissues to the enucleation. Cauterization and hemostasis of the bleeding vessels were performed and suture to separate stitches with 5.0 mononylon thread. The surgical specimen was sent to the Anatomopathology Service of the Clinical Hospital of the Federal University of Pernambuco which provided the dermoid cyst report. Conclusion Excision biopsy is the protocol of choice for cystic lesions, since the treatment is its total enucleation, preferably encapsulated and its diagnosis is conclusive through histological analysis.

*Correspondence to Author: Camilla Siqueira de Aguiar UFPE

How to cite this article:

Camilla Siqueira de Aguiar, Evellyn Rayane Martins de Oliveira, Lohana Maylane Aquino Correia de Lima, Victor Leonardo Mello Varela Ayres de Melo, Maria Luísa Alves Lins, Ricardo Eugenio Varela Ayres de Melo. DERMOID CYST ENUCLEATION IN HEARING PAVILION. International Research Journal of Otolaryngology, 2020, 3:9

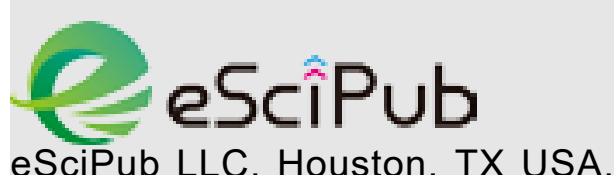
eSciPub LLC, Houston, TX USA. Website: https://escipub.com/

Keywords Dermoid Cyst, Ear, Surgery Oral. 